\title{
Mujeres en las artes escénicas en el Perú y América Latina
}

Lectora, lector:

¿Qué escuchas mientras lees estas palabras? ¿Reconoces los sonidos? Aquí, desde el piso 16 del edificio en el que vivo, la sirena de una ambulancia se abre paso en la avenida. Esa vibración atraviesa mis poros, pero sigo escribiendo. Mis dedos tiemblan sobre el teclado. Escribo: vivo.

Escribir es ir en busca de la fuerza de lo vivo.

La emergencia sanitaria mundial originada por la COVID-19 nos confronta con los escenarios lamentables del capitalismo extractivo y queda al descubierto la inequidad; mantener en pie el derecho a preservar la vida es una lucha diaria. Ante ello, cambian nuestras formas de relacionarnos. Nuestros rituales cotidianos se reinventan, así como los modos en que podemos pensar en el futuro que construimos. Las artes escénicas no son ajenas a estos procesos; al contrario, se nutren de estas experiencias, porque en ellas surgen las búsquedas de creadores y creadoras, y en ellas también afloran las posibles respuestas que permiten recrear nuestro vínculo con el pasado y el presente en que vivimos.

Es en esa perspectiva que la condición del artista que investiga y da cuenta de sus procesos creativos se vuelve un eje central para conocer el potencial de estas experiencias y su lugar en la sociedad. En los últimos años, ante la incorporación de las artes como forma de conocimiento a la institución académica, opera también la búsqueda de la especificidad de esta construcción. Podemos señalar que, a partir de los modos de producción artística, la creación de metodologías y la atención a los procesos de subjetividad que entran en acción al volver sobre la práctica, se abren horizontes diversos en los que el trabajo del 
artista persigue el fin estético y, además, se configura como práctica situada en un contexto que le otorga resonancia a su trabajo.

Una especial atención se puede dar en ese ámbito a la labor de las mujeres en las artes escénicas, y su particularidad como creadoras, porque hoy movilizan tanto una propuesta estética como ética y política, que dialoga con luchas desde la equidad de género, el trabajo con poblaciones vulnerables y la defensa del territorio y sus recursos naturales. Estas creaciones proponen mundos posibles, y edifican imágenes que interpelan los imaginarios y sensibilidades establecidos. Lo escénico ya no se encuentra solo en espacios determinados, sino que el mismo término se expande y nos permite abordar la complejidad de la acción poética.

Es desde esas reflexiones que el número 13 de la revista Conexión, titulado Mujeres en las artes escénicas en el Perú y América Latina, es una respuesta a la crisis desde el campo del arte. Nace del impulso por visibilizar el trabajo artístico y la reflexión sobre él para abrir campos de discusión no solo desde nociones relacionadas con la productividad. Por ello, el eje de los trabajos que componen esta edición gira en torno a las corporalidades y narrativas del «yo» que involucran la mirada y sensibilidad femeninas en esta actividad del pensamiento.

Suely Rolnik propone que

pensar consiste en «escuchar» los afectos, efectos que las fuerzas de la atmósfera del ambiente producen en el cuerpo, las turbulencias que provocan en él y la pulsación de mundos larvarios que, generados en esa fecundación, se le anuncian al saber-de-lo-vivo (2018/2019, p. 81).

Retomo esta idea del saber-de-lo-vivo para acercarnos a la enunciación desde el «yo» como la oportunidad de pensarnos a través de un saber del cuerpo que es relacional y que se deja afectar por los estímulos del ecosistema en el que crea. Es allí donde emerge lo vivo, lo que permite la continuidad que - Rolnik también señala- nos alerta para estar a la altura de la vida. 
Así, a partir de las experiencias de cinco artistas investigadoras latinoamericanas, nos adentramos en procesos íntimos de creación en los que se develan preguntas, cuestionamientos y hallazgos. Marissa Béjar (Perú), Sandra Bonomini (Perú-Brasil), Belén Parrilla (Argentina), Lorena Pastor y Silvia Tomotaki (Perú) eligen construir su lugar de enunciación desde la práctica escénica, y dan cuenta de dichos procesos a partir de la confrontación con los contextos que enmarcan sus creaciones. Por ello, es relevante que estas reflexiones se encuentren guiadas por un «yo» situado en un tiempo y espacio, y que se va reelaborando a sí mismo a través del pensamiento; que discurre, se extravía y se reencuentra con lo que ha germinado, con esas formas otras que aparecen a partir de un vínculo poético con la realidad. Sin embargo, este ejercicio desde el «yo» no se orienta a una búsqueda cerrada en sí misma, sino que impulsa la construcción de esa subjetividad desde la relación con los otros cuerpos que forman parte de la experiencia artística. Todas las autoras vuelven a pasar por su experiencia y conforman un repertorio de discursos encarnados que nos invitan a escuchar con atención.

Marissa Béjar presenta el trabajo de investigación-creación interdisciplinaria (Un) Ser en la ciudad: caminata escénica, realizado en el Centro Histórico de Lima durante los años 2018 y 2019. A través de la mirada de su creadora, compartimos sus apuestas conceptuales desde el giro performativo, así como metodológicas, que hacen visibles los riesgos y resultados de la experiencia que comprometen tanto la subjetividad de los artistas involucrados como la de los caminantes que participaron en la acción, y que la autora propone como seres con entidad y acción. A través de su memoria y las resonancias de su cuerpo, Béjar vuelve a los espacios públicos intervenidos en la obra; estos se despliegan en su escritura y crean un espacio de intimidad que también nos interpela. Sus preguntas y sensaciones nos permiten acompañar a la artista en este viaje de vuelta lleno de desafíos.

Lorena Pastor y Silvia Tomotaki comparten sus reflexiones sobre el Proyecto de Artes Escénicas en el Penal Modelo Ancón II, que se desarrolla con población penitenciaria. A través de sus reflexiones, conocemos cómo se entreteje la metodología del proceso creativo que facilita el trabajo con material testimonial de los internos e internas 
que participan en el proyecto, junto con el lugar de enunciación que también construyen las y los artistas involucrados. Los vínculos que se generan en esta experiencia son un punto importante de la reflexión, ya que no responden a una lógica extractiva que entiende las narrativas personales como mercancías, sino a una puesta en valor de la investigación artística que involucra lo estético y lo ético. Y, aquí, la presencia de los cuerpos de las artistas y la población penitenciaria es vital, porque es en esa convivencia que emerge el proceso creativo y también desde allí se revela la incertidumbre de ese encuentro que permite repensar las nociones de identidad, creación y libertad.

Sandra Bonomini aborda la performance Paso doble de Mirella Carbone, bailarina y coreógrafa peruana que ha logrado gran influencia en las generaciones actuales de creadores de teatro, danza y performance. A partir de dicha pieza, Bonomini explora, con suma delicadeza y sensibilidad, una forma de analizar la experiencia que la incorpore como espectadora de la pieza y que conjure los deseos, intenciones y riesgos que Carbone despliega en su trabajo. Desde la teoría feminista y poscolonial, la autora y su cuerpo se ven implicados, porque apela a las resonancias que aún vibran a través de los años, y nos abre las puertas a los temas latentes de la puesta en escena: género, sexualidad y raza. Cada paso, cada línea y cada punto son también un respiro para continuar entretejiendo teoría y práctica. No es un ejercicio de memoria literal, sino una apuesta por encontrar formas otras de acercarse a lo que palpita vivo y hacerlo comunicable.

Belén Parrilla nos lleva hacia la acción a partir de las movilizaciones feministas en Argentina que exigen la sanción de la Ley de Interrupción Voluntaria del Embarazo. A través de su propuesta, nos acercamos a las intervenciones artísticas que formaron parte de las marchas de 2018 y, en particular, a la fotoperformance iNosotras podemos!, que realiza en colaboración con la artista Alejandra Albán Araujo. La performance se apropia del espacio público y no solo se activa por la presencia de las artistas que diseñan el dispositivo, sino por las mujeres que son convocadas por la experiencia para prepararse, posar frente a una cámara y ser fotografiadas. Ese gesto, tan pequeño en medio del estallido colectivo, genera zonas de intimidad donde los cuerpos de mujeres de diversas generaciones conviven, y podemos 
leer cómo los discursos en pugna en las marchas son encarnados y resignificados.

Todos estos relatos tienen como punto de partida la implicación del «yo» en la organización de la experiencia para, desde allí, trazar coordenadas sensoriales y sensibles que las interpelen durante el acto de dar cuenta de una misma: ¿cómo me hago cargo de mi propia opacidad al decir «yo»?, ¿qué coordenadas me permiten situar mi práctica artística y sus implicancias éticas?, ¿con qué estrategias escucho las resonancias de la experiencia en mi cuerpo para encontrar sentido en el presente, aun cuando la experiencia escénica se ha desvanecido? Esta condición sobre lo efímero es abordada con un brillo particular por Didanwy Kent (2019), porque lo efímero deja huella, y es desde esa resonancia en el cuerpo que este se pone en juego. Podemos preguntarnos cuáles son los límites de esta enunciación, pero la reunión de estos artículos es más una invitación a descubrir de qué forma las artistas e investigadoras del número han planteado sus propuestas a partir de la corporalidad de su escritura.

Escribir es encontrar la fuerza de lo vivo, activar aquello que resuena en nuestros cuerpos como experiencia, y nos vincula con nuestras maneras de habitar el mundo.

Ante la proximidad del Bicentenario de la Independencia, numerosas son las iniciativas que se vinculan con la necesidad de difundir el trabajo silenciado de muchas mujeres en diversos campos, entre ellos, el arte. Por ello, consideramos que los artículos aquí presentados no agotan la amplitud de procesos creativos que tenemos por conocer, en los que las mujeres han sido y son guía tenaz como actrices, bailarinas, cantantes, compositoras, coreógrafas, directoras, docentes, dramaturgas, escenógrafas, gestoras, intérpretes investigadoras, jefas de tramoya, luminotécnicas, performeras, productoras, entre otros frentes. Esperamos que este esfuerzo impulse a conocer ávidamente sobre la labor de la mujer en las artes escénicas más allá de las fronteras.

Finalmente, y de modo muy especial, quisiera señalar que esta edición es posible por una complicidad entre el Departamento Académico de Artes Escénicas y el Departamento Académico de Comunica- 
ciones de la Pontificia Universidad Católica del Perú. Sin el cuidado y especial esfuerzo de los involucrados e involucradas, este número temático pudo quedar confinado. No fue así: los ojos de ustedes, lectores y lectoras, recorren estas palabras que poco a poco van llegando al final. Que las experiencias que aquí se contienen viajen hacia ustedes y pasen por sus cuerpos para rehabitar sus memorias.

Y que allí se agiten, sutiles y fértiles.

Vivas.

Lucero Medina Hú

Profesora auxiliar del Departamento Académico de Artes Escénicas Coordinadora de la especialidad de Creación y Producción Escénica Pontificia Universidad Católica del Perú

\section{REFERENCIAS}

Kent, D. (2019). El «respectador» ante la liminalidad de la experiencia teatral. En J. Dubatti (Coord. y Ed.), Poéticas de la liminalidad en el teatro II (pp. 165-180). Escuela Nacional Superior de Arte Dramático.

Rolnik, S. (2019). Esferas de la insurrección. Apuntes para descolonizar el inconsciente (Trads. C. Palmeiro, M. Cabrera y D. Kraus). Tinta Limón Ediciones. (Trabajo original publicado en 2018) 